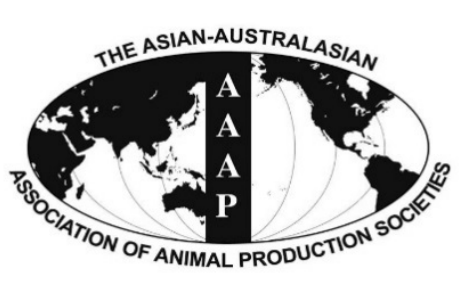

Open Access

Asian Australas. J. Anim. Sci.

Vol. 29, No. 6 : 879-886 June 2016

http://dx.doi.org/10.5713/ajas.15.0597

www.ajas.info

pISSN 1011-2367 elSSN 1976-5517

\title{
Effects of Weaning and Spatial Enrichment on Behavior of Turkish Saanen Goat Kids
}

\author{
Cemil Tölü*, Semra Göktürk ${ }^{1}$, and Türker Savaş \\ Department of Animal Science, Agriculture Faculty, Çanakkale Onsekiz Mart University, Çanakkale 17020, Turkey
}

\begin{abstract}
As is in all economic activities, the highest yield per unit area is the main goal in animal production, while addressing the temperamental needs of animals often is ignored. Animal welfare is not only an ethical fact; it also has an economic value. Spatial environmental enrichment contributes positively to animal welfare by addressing their behavioral and mental requirements. The present study was conducted to determine the effects of weaning and spatial environmental arrangements on behaviors of goat-kids. Experimental groups were arranged in structured and unstructured spatial environments. Roughage feeder, semi-automatic concentrate feeder, bunk, bridge, and wood block were placed in the structured environment. No equipment was placed in the unstructured environment and paddock sides were enclosed with an iron sheet to prevent bipedal stance and to provide environmental isolation. In the study 10 male and 10 female Turkish Saanen goat kids were used in each group. Spatial environmental arrangements did not have significant impacts on the growth performance of kids ( $>0.05$ ). All objects in the structured group were accepted by the kids. Average use ratios of roughage feeder, semi-automatic concentrate feeder, bunk, bridge and wood block were observed as $19.3 \%, 14.0 \%, 12.6 \%$, $3.8 \%$, and $0.7 \%$, respectively. There were significant differences between before- and after-weaning in use of all objects except for underneath bridge $(\mathrm{p} \leq 0.05)$. Concentrate feed consumption, locomotion, and resting behaviors in kids showed significant differences by structural group and growth period. Roughage consumption was similar between groups, while it differed by growth period ( $\leq \leq 0.05$ ). Interaction frequency was significantly higher in structured group $(\mathrm{p}=0.0023)$. Playing behavior significantly differentiated based on the growth period rather than on groups $(\mathrm{p} \leq 0.05)$. Playing behavior significantly decreased after weaning. Abnormal oral activity was significantly higher in the structured group before weaning $(\mathrm{p} \leq 0.05)$. Despite there being no installations facilitating climbing and bipedal stance, the kids of the unstructured group were able to exhibit $1 / 3$ as much bipedal stance behavior as the kids of the structured group through leaning over slippery paddock wall or over their groupmates. Bipedal stance behavior of unstructured group was similar before and after weaning, while bipedal stance behavior before weaning was about 2 times that of after weaning in structured group. It was concluded that unstructured environmental arrangement limited the behavior repertoire of the goat kids. (Key Words: Environmental Enrichment, Turkish Saanen, Growth, Bipedal Stance, Animal Welfare)
\end{abstract}

\section{INTRODUCTION}

As it is in all economic activities, the highest yield per unit area is the main goal in animal production. Nowadays, the demands of consumers are not only limited to the product quality but also the quantity. Laity are also interested in the conditions under which the products are produced. In this sense, it is expected that during the

\footnotetext{
* Corresponding Author: Cemil Tölü. Tel: +90-286-218-00-18 (1326), Fax:+90-286-218-05-45, E-mail: cemiltolu@comu.edu.tr ${ }^{1}$ Çanakkale Sheep and Goat Breeders Association, Çanakkale 17000 , Turkey.

Submitted Jul. 14, 2015; Revised Aug. 29, 2015; Accepted Sept. 23, 2015
}

production of animal products the animals are "happy". Consequently, animal welfare is not only an ethical fact, but also an element with growing economic value.

Since the surrounding environment of domestic animals is shaped by humans, their biological needs should be considered by us. "Behavioral needs" are among such requirements (Poole, 1992; Jensen and Toates, 1993). It is reported that the adjustment and enrichment of the housing conditions and social environment on the behavioral repertoires of the animals promotes animal welfare (Newberry, 1995; Van Loo et al., 2002; Wells, 2004). Environmental structuring implementations should allow animals to exhibit their normal behaviors in their repertoire 
and aim to diminish abnormal behaviors (Mason et al., 2007). Positive impacts of environmental structuring on behaviors and welfare of various animal species were reported by several researchers (Van Loo et al., 2002; Wells, 2004). Besides the positive effects of environmental structuring on animal behavior and welfare, affirmative impacts were also reported on feed consumption and conversion (Flint and Murray, 2001; Rosas-Trigueros et al., 2009).

It was pointed out in previous studies that environmental structuring programs require time and financial inputs, thus the efficiency of the program to be selected should be well-defined. It was also pointed out that structuring objects should not create a danger for animals and they should easily be cleaned (Schmidt, 2003).

Performance of normal animal behaviors is a significant indicator of animal welfare in a certain environment. Exhibition of normal behavior is among five basic freedoms constituting animal welfare specified by Farm Animal Welfare Council (FAWC, 2001). Researchers reported positive effects of spatial structuring on performance of behaviors of animals (Newberry, 1995; van de Weerd and Day, 2009). On the other hand, if animals do not show abnormal behaviors, this does not necessarily mean that the environment has a positive effect (Poole, 1992). Absence of abnormal behaviors can be seen favorable for the welfare of the animals, but the quality and quantity of the behaviors is also important.

Goats have a high urge to move. Although they are social animals, their loyalty to the herd is not as strict as, for example, sheep. Goats behave more individually than sheep. Another behavior of goats different from other domestic ruminants is their browsing behavior. Goats can browse higher than sheep and cows (Sanon et al., 2007) and at least $10 \%$ of foraging time is spent in bipedal mode (Dove, 2010). It is known that even young goat kids exhibit this behavior.

The present study was conducted to investigate the effects of spatial environmental arrangements on the behaviors of kids. In particular, browsing derived bipedal stance behavior was given special attention. Utilization ratios of the structuring objects were also determined.

\section{MATERIALS AND METHODS}

The research protocol of the current study was approved by the Animal Ethic Committee of Çanakkale Onsekiz Mart University (Approval number: 2009/13).

\section{Study design}

The present study was conducted at the small ruminant unit of Technological and Agricultural Research Centre of Çanakkale Onsekiz Mart University. Experimental groups were arranged as structured environment enriched with different objects and unstructured environment without any objects. Paddock size of each group was $5.50 \times 5.20 \mathrm{~m}$. Roughage feeder, semi-automatic concentrate feeder, ladder double-story "bunk", ladder walking "bridge" and wood block were placed in structured environment (Figure 1). No equipment was placed in unstructured environment and paddock sides were enclosed with sheet iron to prevent bipedal stance behavior and to provide environmental isolation. A space fifteen $\mathrm{cm}$ from one side of the paddock of the unstructured group was separated by a fence into which animals could insert their heads and access roughage and a semi-automatic concentrate feeder apparatus.

\section{Animals and management}

A total of 40 Turkish Saanen goat-kids were used in the experiment. The kids were divided into two groups; each group contained 10 female and 10 male animals. Following birth, kids stayed continuously with their mothers until the age of 7 days and then were separated into experimental groups at 8th day based on gender, type of birth and birth weight. Just adjacent to the growing paddocks were paddocks without any installations where the kids stayed with their mothers at night until weaning (61 \pm 6 days). Kids were separated from mothers at 09:00 and reunited at 18:00. Kids stayed in experimental paddocks during the day hours and stayed in adjacent paddocks with their mothers at nights until weaning. Following weaning, they stayed continuously in experimental paddocks. In growing paddocks, roughage and concentrate feed, water and licking block were supplied ad libitium. Alfalfa roughage was provided in fenced roughage feeder, while concentrate feed was provided by a semi-automatic feeder for the structured group (Figure 1). However, in the unstructured group a space separated with fences at a certain location of the paddock was used as feeder space. Roughage was provided over a concrete floor adjacent to fences, and concentrate feed was provided within $8 \mathrm{~cm}$-high wooden feeder. Water was supplied in 30-liter plastic containers in both groups. Kids were supplied with alfalfa roughage $(91.20 \%$ dry matter [DM], $18.90 \%$ crude protein [CP], 42.11\% neutral detergent fiber [NDF], 31.10\% acid detergent fiber [ADF], 2,200 kcal metabolizable energy [ME]) and pelletized concentrate feed $(92.85 \% \mathrm{DM}, 17.34 \% \mathrm{CP}, 36.43 \% \mathrm{NDF}$, $13.50 \%$ ADF, 2,600 kcal ME). Dry matter contents of feed samples were determined in accordance with the methods specified in AOAC (1990) and carbohydrate analyses were carried out in accordance with the methods specified in ANKOM (2005). Nitrogen (N) content was determined in a Carbon-Nitrogen Auto Analyzer (LECO TruSpec CN, St Joseph, MI, USA) and then crude protein content was determined using the formula of $\mathrm{CP}=\mathrm{N} \times 6.25$ (Tölü et al., 2012).

Group-based daily feed intake of the kids was 


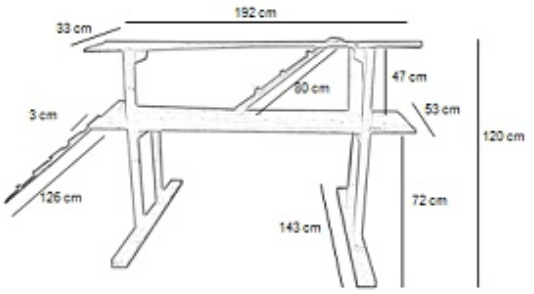

a) Bunk

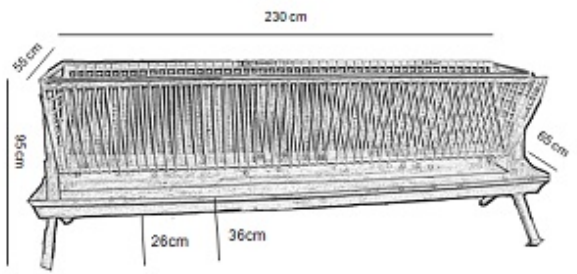

d) Roughage feeder

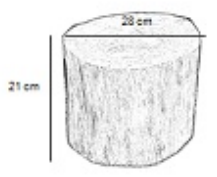

e) Wood block

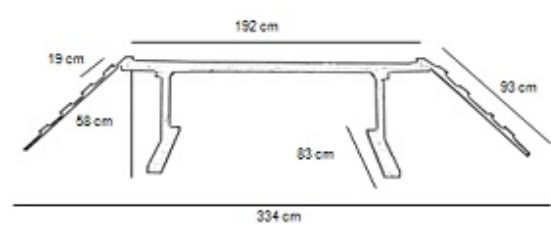

b) Bridge

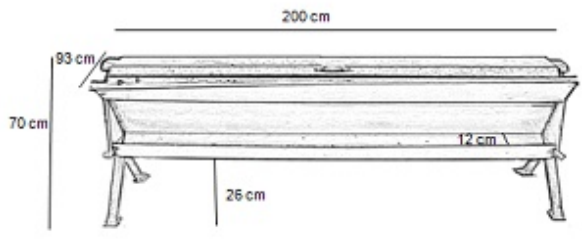

d) Semi-automatic concentrate feeder

Figure 1. The enrichment objects of the structured group.

determined at 20 days of age. The experiment was terminated when the kids reached to an average age of $128 \pm 6$ days. Live weight measurements were performed at the beginning of the experiment, at weaning and at the end of the experiment with a platform balance $( \pm 10 \mathrm{~g})$. The group-based feed intake of the kids was weekly measured.

\section{Behavior observations}

Direct observations were made for behavioral observations. Two experienced observers performed the continuous and time sampling observations for each group. Observations were performed between the hours 09:30 to $11: 30$ and between the hours $14: 30$ to $16: 30$ once a week for 16 weeks. Ten-minute intervals were used in time sampling. With time sampling method, eating, lying, standing and locomotion behaviors were recorded. During the behavior observations with the time sampling method, we also recorded where the behaviors took place. From these data, the ratio of the object use was calculated. With continuous sampling method, climbing, step up on an object, interaction, sexual behavior, playing and abnormal oral activity behaviors were recorded. The behavioral characteristics considered in this study are defined below:

Eating: Roughage or concentrate feed consumption or tendency for consumption,

Lying: Resting of kids without ruminating in lying position,
Standing: Resting of kids without ruminating in a still standing position,

Ruminating: Ruminating of kids either in standing or lying position,

Locomotion: Moving of kids,

Bipedal stance: Standing of kids on their rear legs by leaning or non-leaning the front legs on any objects,

Step up on an object: On the objects with four legs,

Interaction: Interactions of kids with each other, either for playing or for serious purposes,

Sexual behaviors: Jumping of male kids on their groupmates similar to mating behavior,

Playing: Jumping up and down of kids by running, without any meaningful reasons,

Abnormal oral activity: Licking, chewing or biting on paddock installations and/or hairs of other kids.

\section{Statistical analysis}

SAS (1999) statistical software was used for data analysis. In birth weight analysis of the kids, group (structured and unstructured), gender $(\hat{\partial},+$ ) and type of birth (single, multiple) and relevant interactions were included in variance analysis. Weaning weights and live weights at the end of the experiment were also analyzed with the same method, but birth weight $(\mathrm{kg})$ and weaning age (day) were included in the model as covariates. In the analysis of behavioral traits observed through time 
sampling, generalized estimating equations (GEE) of logistic regression method was used with the help of proc GENMOD. This method was used due to the combination of repeated measurements of a binomial response and both categorical and continuous explanatory variables. A discrete model with fixed factors of group (structured and unstructured), gender $(\hat{\sigma}, \hat{+})$, growth period (before weaning and after weaning), date of observation nested in growth period $(1, . ., 16)$ were used. The post-hoc analyses of the data analyzed with the discrete model were made according to the WALD chi-square test. The behavioral data observed through continuous observation method were analyzed by using the method of repeated measurements variance analysis. In these analyses, group (structured and unstructured), gender ( $\lesssim,+$ ), and growth period (before weaning and after weaning) were included as fixed factors. Logarithmic transformation $\left(\log _{10}[\mathrm{y}+10]\right)$ was applied to continuous observation data to meet the pre-condition of variance analysis. TUKEY test was used in post-hoc analyses of the continuous data.

\section{RESULTS}

\section{Performance}

No significant difference was observed between observation period-based live weights of groups ( $p>0.05$; Table 1). According to the values from Table 1, we calculated average live weight gains: the daily live weight gain before weaning was $186 \mathrm{~g}$ in unstructured group and $185 \mathrm{~g}$ in structured group, while after weaning daily live weight gains were calculated as $195 \mathrm{~g}$ and $193 \mathrm{~g}$, respectively. Roughage consumption followed a fluctuating course while concentrate feed consumption had a more stable course and increasing trend throughout the
Table 1. Least square means (LSM), standard errors (SE) and pvalues for period-based live weights of the groups

\begin{tabular}{lcccccc}
\hline \multirow{2}{*}{$\begin{array}{l}\text { Period weights } \\
(\mathrm{kg})\end{array}$} & \multicolumn{2}{c}{ Unstructured group } & \multicolumn{3}{c}{ Structured group } & \multirow{2}{*}{ p-values } \\
\cline { 2 - 3 } \cline { 5 - 6 } & LSM & SE & & LSM & SE & \\
\hline Birth weight & 3.64 & 0.04 & & 3.62 & 0.00 & 0.6636 \\
Initial & 6.27 & 0.19 & & 6.24 & 0.19 & 0.9094 \\
Weaning & 15.80 & 0.45 & & 15.25 & 0.44 & 0.3679 \\
Final & 28.50 & 0.59 & & 28.36 & 0.58 & 0.8626 \\
\hline
\end{tabular}

Initial, the kids at 8 days of age; Weaning, the kids at 61 days of age; Final, the kids at 128 days of age.

experiment. Average concentrate feed consumption of unstructured and structured groups were determined as 628 $\mathrm{g} / \mathrm{d}$ and $657 \mathrm{~g} / \mathrm{d}$ respectively, while roughage consumptions were $360 \mathrm{~g} / \mathrm{d}$ and $270 \mathrm{~g} / \mathrm{d}$. These values indicated that 3.62 $\mathrm{kg}$ concentrate feed was consumed per $\mathrm{kg}$ live weight gain in unstructured group and $3.80 \mathrm{~kg}$ in structured group throughout the experiment. Total feed conversion rate per $\mathrm{kg}$ live weight was calculated as $5.69 \mathrm{~kg}$ in unstructured group and $5.36 \mathrm{~kg}$ in structured group.

\section{Use of structured object}

Kids used all structural objects placed in structured group both before and after weaning (Figure 2). With regard to object-use ratios, there were significant differences between before and after weaning in use of all objects except for underneath bridge $(\mathrm{p} \leq 0.05)$. Average use ratios of roughage feeder, semi-automatic concentrate feeder, bunk, bridge and wood block were observed as $19.3 \%, 14.0 \%$, $12.6 \%, 3.8 \%$, and $0.7 \%$, respectively. The kids used all objects before weaning in $48.19 \%$ of the observation times, while the value increased after weaning to $52.79 \%$. The kids mostly used bunk tops. Following the weaning, the kids increased the uses of underneath semi-automatic

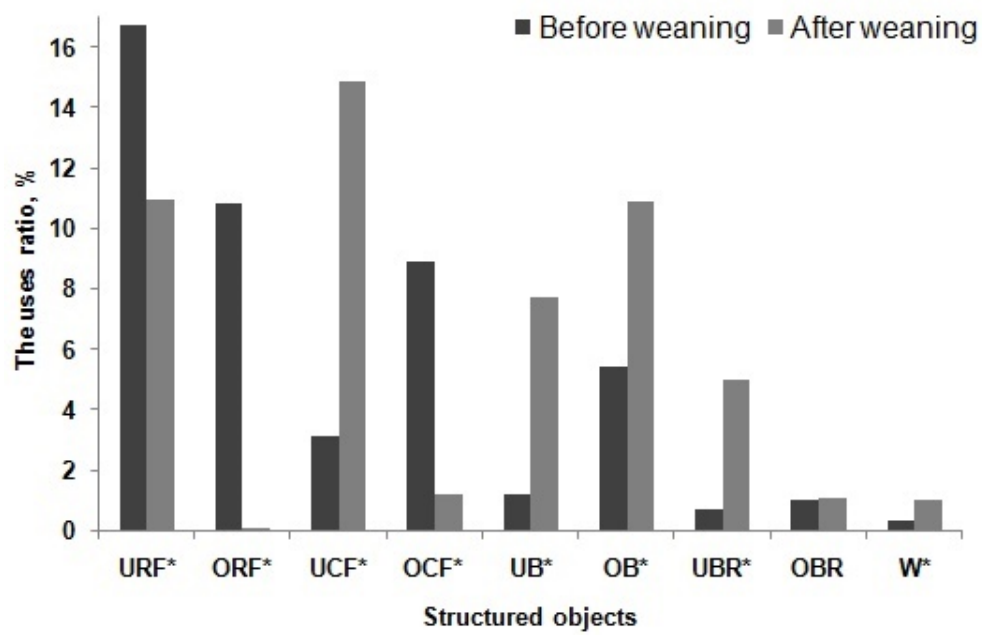

Figure 2. Use ratios of objects placed in structured group before and after weaning. * The differences in structural object uses before and after weaning were significant according to WALD chi-square test, $\mathrm{p} \leq 0.05$; URF, underneath roughage feeder; ORF, the roughage feeder top; UCF, underneath semi-automatic concentrate feeder; OCF, the semi-automatic concentrate feeder top; UB, underneath bunk; OB, the bunk top; UBR, underneath bridge; OBR, the bridge top; W, wood block. 


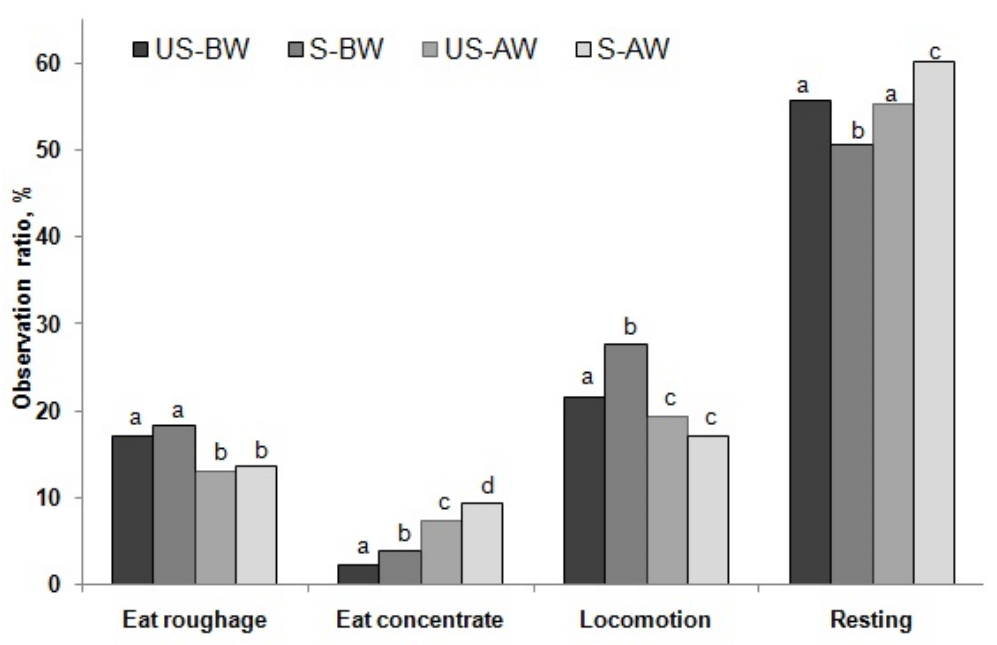

Figure 3. Relative behavior observation averages of the groups before and after weaning. US-BW, unstructured before weaning; S-BW, structured before weaning; US-AW, unstructured after weaning; S-AW, structured after weaning; the differences in group averages indicated with different letters are significant according to WALD chi-square test, $\mathrm{p} \leq 0.05$.

concentrate feeder, bunk, bridge and wood block, but there were significant decreases in uses of underneath roughage feeder and semi-automatic concentrate feeder top $(\mathrm{p} \leq 0.05)$. Roughage feeder top was hardly used for climbing after weaning. Object use ratios of the kids ordered from higher to lower as roughage feeder, semi-automatic concentrate feeder, bunk, bridge and wood block are shown in Figure 2.

\section{Behavior observation}

Concentrate feed consumption, locomotion, and resting behaviors in kids showed significant differences by structural group and growth period (Figure 3). Roughage consumptions were similar in groups, while they differed by growth period $(p \leq 0.05)$. Locomotion behavior decreased after weaning, and the differences by groups were only visible before weaning $(\mathrm{p} \leq 0.05)$. Resting behaviors of the animals were similar before and after weaning in unstructured group, but in structured group there was a difference in favor of after weaning $(\mathrm{p} \leq 0.05)$.

Despite having no installations to facilitate climbing and bipedal stance, the kids of the unstructured group were able to exhibit $1 / 3$ as much bipedal stance behavior as the kids of the structured group through leaning over a slippery paddock wall or over their groupmates (Figure 4; $<<0.0001$ ). Bipedal stance behavior of unstructured group was similar before and after weaning. On the other hand, in structured group, bipedal stance behavior before weaning was about 2 times that of after weaning (Figure $4 ; \mathrm{p} \leq 0.05$ ). Within a

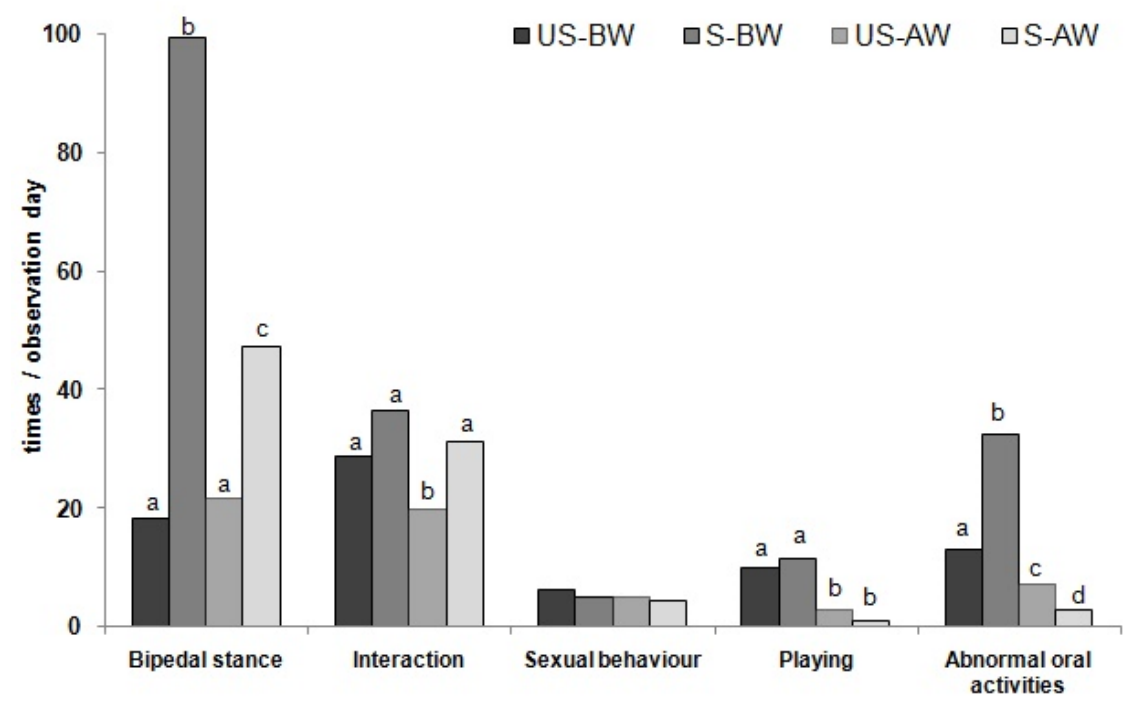

Figure 4. Observation day total behavior frequency of the groups based on weaning period. US-WB, unstructured before weaning; SWB, structured before weaning; US-AW, unstructured after weaning; S-AW, structured after weaning; the differences in group averages indicated with different letters are significant according to TUKEY test, $\mathrm{p} \leq 0.05$. 
total of 64 hours observation period (16 weeks $\times 4$ hours), structured group exhibited bipedal stance behavior 4,271 times, while the number was 1,367 in the unstructured group. It was also remarkable that the kids exhibited bipedal stance behavior 16 times in the unstructured group without leaning any objects and groupmates. In structured group, climbing over an object was exhibited about half of the bipedal stance behavior.

The behaviors of the groups observed through continuous observation method, except for sexual behavior, were significantly different before and after weaning (Figure $4 ; p \leq 0.05$ ). Interaction frequency, which can be characterized as an aggressive behavior, was significantly higher in structured group (Figure 4; $\mathrm{p}=0.0023$ ). The interactions between the kids of structured group were similar to each other before and after weaning, while the ratio in unstructured group after weaning was significantly different from the other growth period (before weaning) and the structured group $(p \leq 0.05)$. Sexual interaction and jump up and down playing of the groups were closer to each other, whereas playing behavior significantly differentiated based on the growth period rather than on groups $(\mathrm{p} \leq 0.05)$. Significant decreases were observed in playing behavior after weaning. Although abnormal oral activity of the groups and growth periods was not significantly different, the value was higher in structured group before weaning and lower after weaning $(\mathrm{p} \leq 0.05)$.

\section{DISCUSSION}

\section{Performance}

The effects of different spatial environments on weaning and end-of-experiment live weights of the kids were not significant (Table 1). Savaş et al. (2010) found similar results on the same genotype in different spatial environment groups. Flint and Murray (2001) investigated the effects of structured environment on feed conversion of castrated goats and observed a positive impact of structured environment on feed conversion. Beattie et al. (2000) reported that structured and unstructured environments did not have significant effects on live weight gains of pigs until the age of 14 weeks, but structured environment had significant positive effects on feed conversion ratios.

\section{Uses of structured object}

The kids used all of the objects placed in structured group (Figure 2). While the objects were used both before and after weaning, the roughage feeder top was hardly used after weaning. Utilization ratios of the objects, except for the bunk top, were significantly different before and after weaning $(p \leq 0.05)$. The kids used the bottom of the roughage feeder and, the bottom and top of concentrate feeder for resting. They used the top of semi-automatic concentrate feeder, top of bridge, and wood block during locomotion. The bunk was mostly used for resting. Similarly, the kids looked for clean and more comfortable places for lying and thus preferred underneath feeders (roughage and concentrate) beneath and bunk tops. The kids also preferred beneath the objects since they probably wanted to feel safe when they were resting. Since bridge, wood block and semi-automatic concentrate feeder top, especially after weaning, do not have a comfortable lying surface, the kids preferred these locations during locomotion rather than for resting. Barth et al. (2005) reported that entire stories of multi-story resting niches (similar to bunks of the present study) were used by the goats for resting.

\section{Behavior observation}

The kids spent $1 / 2$ of their time for resting, $1 / 4$ for activity and remaining time for roughage and concentrate feed consumption in both groups (Figure 3). The frequencies of these behaviors differ significantly between before and after weaning $(\mathrm{p} \leq 0.05)$, except for resting behavior in the unstructured group $(p \leq 0.05)$. Higher roughage eating behavior before and after weaning than concentrate feed eating behavior was observed. Similar results were also reported by Morand-Fehr et al. (1982). Kids in their growing period spend most of their time for resting (Ataşoğlu et al., 2008). Lying behavior varies based on animal age, locomotion and feed consumption (Ataşoğlu et al., 2008). In the present study, kids spent most of their time resting and they had higher feed consumption and resting durations and lower locomotion after weaning (only in structured group) than before weaning (Figure 3). RosasTrigueros et al. (2009) reported that Murciano-Granadina suckling dairy goat-kids had higher ratios of ingestion, body care, locomotion, exploration, rest-sleep behaviors in a structured environment.

Despite no installations facilitating bipedal stance, the kids of unstructured group exhibited bipedal stance behavior through leaning on slippery paddock wall or on their groupmates (Figure 4; $\mathrm{p}<0.0001$ ). It was also remarkable in unstructured group that the kids exhibited 16 times bipedal stance behaviors without leaning on objects or groupmates. This behavior is identical to the dust-bathing of hens in cages without substrate. Savaş et al. (2010) argued that bipedal stance behavior was an essential behavior of goat kids. Higher frequencies of bipedal stance behavior at before weaning than after weaning indicate that younger goat kids have a higher demand for an enriched environment, that promotes the bipedal stance behavior (Figure 2).

The kids of structured group stepped up over an object 1,889 times. Savaş et al. (2010) carried out a study with unstructured and, structured groups to observe the climbing 
behaviors of kids in fenced paddocks and reported identical climbing plus stepping over an object behavior frequency for all groups. Such a case indicated that entire mobility of the kids were composed of climbing and stepping over an object behaviors, and thus behavioral needs of the kids at that age should be satisfied (Poole, 1992; Jensen and Toates, 1993). Our results suggest that behavioral needs of the kids were not met in an unstructured environment.

Less frequent significant interaction behavior was observed after weaning in the unstructured group (Figure 4; $\mathrm{p}=0.0023$ ). Higher interaction frequencies of structured group may result from object shares (Tölü and Savaş, 2007). Beattie et al. (2000) reported that structured environments significantly decreased interactive and aggression behaviors of pigs. Frequency of playing behavior, composed of running, jumping up and down, was significantly affected by the growth period rather than by the group and playing behaviors decreased after weaning in unstructured group (Figure 4; $\leq \leq 0.05$ ). Newberry et al. (1988) reported that piglets commonly preferred running for play and indicated the highest level of play at 2 to 6 weeks of age, followed by a decrease. The kids of the present study were also highly mobile at the same ages and exhibited playing behaviors. However, since they had to spend more time for feed consumption after weaning rather than taking their feeds from their mothers in a shorter time, they had less time for playing and thus their playing frequencies decreased with their increasing ages. Abnormal oral activity varied based on groups and growth periods. It was high before weaning in structured group and even higher after weaning in unstructured group $(\mathrm{p} \leq 0.05)$. The fence construction of the paddock side separators in structured group allowed the kids to insert their mouths and the curiosity of young kids might have stimulated abnormal oral activities. It was reported that environmental structuring decreased stereotype abnormal activities of wild animals housed in zoos (Mason et al., 2007). On the other hand, Vinke et al. (2004) reported increased behavioral diversity and indifferent stereotype behaviors for minks with cage structuring. Low abnormal oral activity levels in both groups of the present study and significant growth periodbased changes limit the further discussions on this issue.

\section{CONCLUSION}

It was observed that two different spatial environments (structured and unstructured) did not differentiate growth performance of the kids. However, it is clear that the goat kids in a structured environment exhibit greater behavioral repertoire. The enrichment objects used in this study were well accepted by the goat kids. In the unstructured environmental group, bipedal stance behavior of the kids through leaning over a flat and slippery surface, using their groupmates for bipedal stance and even standing on their hind legs without leaning over any surface indicated that bipedal stance behavior is an essential behavior for goats. It was finally concluded that unstructured environment affected the behavior repertoire of the goat kids in quantity and quality.

\section{CONFLICT OF INTEREST}

We certify that there is no conflict of interest with any financial organization regarding the material discussed in the manuscript.

\section{ACKNOWLEDGMENTS}

Authors wish to thank TÜBİTAK for financial support provided within the scope of 1100009 numbered project, Dr. İ. Yaman Yurtman for his valuable scientific contribution, Dr. Cem Ömer Egesel for his help in English editing of this article and Res.Asst. Arzu Üçtepe for her helps in behaviorial observations.

\section{REFERENCES}

ANKOM. 2005. Procedures for NDF, ADF, and ADL Analyses. http://www.ankom.com Accessed June 15, 2010.

AOAC. 1990. Official Methods of Analysis. 15th ed. Association of Official Analytical Chemists, Arlington, VA, USA.

Atasoğlu, C., İ. Y. Yurtman, T. Savaş, M. Gültepe, and O. Özcan. 2008. Effect of weaning on behavior and serum parameters in dairy goat kids. Anim. Sci. J. 79:435-442.

Barth, K., D. Ordolff, and C. Mayer. 2005. Investigations of resting areas designed for goats (Eds. J. Heß and R. Gerold). Kassel University Press, Hessen, Germany. pp. 357-358.

Beattie, V. E., N. E. O'Connell, and B. W. Moss. 2000. Influence of environmental enrichment on the behaviour, performance and meat quality of domestic pigs. Livest. Prod. Sci. 65:71-79.

Dove, H. 2010. Ingestive behavior, diet selection and feed intake. In: Goat Science and Production (Ed. S. G. Solaiman). Wiley Blackwell Publications, 2121 State Avenue, Ames, IA 500148300, USA. pp. 179-193.

FAWC. 2001. In term report on the animal welfare implications of farm assurance schemes. Farm Animal Welfare Council, London, UK.

Flint, M. and P. J. Murray. 2001. Lot-fed goats - the advantages of using an enriched environment. Aust. J. Exp. Agric. 41:473476.

Jensen, P. and F.M. Toates. 1993. Who needs 'behavioural needs'? Motivational aspects of the needs of animals. Appl. Anim. Behav. Sci. 37:161-181.

Mason, G., R. Clubb, N. Latham, and S. Vickery. 2007. Why and how should we use environmental enrichment to tackle stereotypic behaviour? Appl. Anim. Behav. Sci.102:163-188.

Morand-Fehr, P., J. Hervieu, P. Bas, and D. Sauvant. 1982. Feeding of young goats. Proc. III International Conf. Goat Prod. Dis., Tucson, AZ, USA. pp. 90-104. 
Newberry, R. C. 1995. Environmental enrichment: Increasing the biological relevance of captive environments. Appl. Anim. Behav. Sci. 44:229-243.

Newberry, R. C., D. G. M. Wood-Gush, and J. W. Hall. 1988. Playful behaviour of piglets. Behav. Proc. 17:205-216.

Poole, T. B. 1992. The nature and evolution of behavioural needs in mammals. Anim. Welf. 1:203-220.

Rosas-Trigueros, A. P., J. O. Salaverri, J. A. C. Duran, and A. J. Quiles Sotillo. 2009. Effect of environmental enrichment on the behaviour and welfare of suckling dairy goat kids in confinement. 43rd Congress of the International Society for Applied Ethology, Cairns Convention Centre, Australia.

Sanon, H. O., C. Kabore-Zoungrana, and I. Ledin. 2007. Behaviour of goats, sheep and cattle and their selection of browse species on natural pasture in a Sahelian area. Small Rumin. Res. 67:64-74.

SAS Institute Inc. 1999. SAS/STAT User's Guide: Version 8. SAS Institute Inc., Cary, NC, USA.

Savaş, T., C. Tölü, H. I. Akbağ, B. Coşkun, and İ. Y. Yurtman. 2010. Is "Bipedal Stance" an essential behaviour of goat kids? (Ed. C. Ataşoğlu). Çanakkale Onsekiz Mar University printing Press, Çanakkale, Turkey. pp. 106-109.
Schmidt, C. 2003. Environmental Enrichment for Laboratory Rats and Mice. Ph.D. Thesis, Freie University, Berlin, Germany.

Tölü, C. and T. Savaş. 2007. A brief report on intra-species aggressive biting in a goat herd. Appl. Anim. Behav. Sci. 102: 124-129.

Tölü, C., İ. Y. Yurtman, H. Baytekin, C. Ataşoğlu, and T. Savaş. 2012. Foraging strategies of goats in a pasture of wheat and shrubland. Anim. Prod. Sci. 52:1069-1076.

Van de Weerd, H. A. and J. E. L. Day. 2009. A review of environmental enrichment for pigs housed in intensive housing systems. Appl. Anim. Behav. Sci. 116:1-20.

Van Loo, P. L. P., C. L. J. J. Kruitwagen, J. M. Koolhaas, H. A. Van de Weerd, L. F. M. Van Zutphen, and V. Baumans. 2002. Influence of cage enrichment on aggressive behaviour and physiological parameters in male mice. Appl. Anim. Behav. Sci. 76:65-81.

Vinke, C. M., R. B. Van Den, and B. M. Spruiljt. 2004. Anticipatory activity and stereotypical behaviour in American Mink (Mustela vison) in three housing systems differing in the amount of enrichments. Appl. Anim. Behav. Sci. 89:145-161.

Wells, D. L. 2004. A review of environmental enrichment for kennelled dogs, Canis familiaris. Appl. Anim. Behav. Sci. 85:307-317. 